\title{
SASS: South African Simulation Survey - a review of simulation-based education
}

\author{
R Swart, ${ }^{1,2}$ R Duys, ${ }^{1}$ ND Hauser ${ }^{2}$ \\ ${ }^{1}$ Department of Anaesthesia and Perioperative Medicine, University of Cape Town and Groote Schuur Hospital, Western Cape, South Africa \\ ${ }^{2}$ Department of Anaesthesia, Fiona Stanley and Fremantle Hospital Group, Perth, Western Australia \\ Corresponding author, email: robswart6@gmail.com
}

Background: Simulation-based education (SBE) has been shown to be an effective and reproducible learning tool. SBE is used widely internationally. The current state of SBE in South Africa is unknown. To the best of our knowledge this is the first survey that describes the use and attitudes towards SBE within South Africa.

Methods: An online survey tool was distributed by email to: i) the South African Society of Anaesthesiologists (SASA) members; and ii) known simulation education providers in South Africa. The respondents were grouped into anaesthesia and non-anaesthesia participants. Descriptive statistics were used to analyse the data. Ethics approval was obtained: HREC REF 157/2017.

Results: The majority of the respondents provide SBE and integrate it into formal teaching programmes. There is a will amongst respondents to grow SBE in South Africa, with it being recognised as a valuable educational tool. The user groups mainly targeted by SBE, were undergraduate students, medical interns, registrars and nurses. Learning objectives targeted include practical skills, medical knowledge, critical thinking and integrated management. Amongst anaesthesia respondents: the tool most commonly used to assess the quality of learner performance during SBE, for summative assessment, was 'expert opinion' (33\%); the most frequent methods of evaluating SBE quality were participant feedback (42\%) and peer evaluation (22\%); the impact of SBE was most frequently assessed by informal discussion (42\%) and learner feedback (39\%). In anaesthesia SBE largely takes place within dedicated simulation facilities on site (47\%). Most respondents report access to a range of SBE equipment. The main reported barriers to SBE were: finance, lack of trained educators, lack of equipment and lack of protected time. A limited number of respondents report engaging in SBE research. There is a willingness in both anaesthesia and non-anaesthesia groups ( $96 \%$ and $89 \%$ respectively) to collaborate with other centres.

Conclusion: To the best of our knowledge this publication provides us with the first cross-sectional survey of SBE in anaesthesia and a selection of non-anaesthetic respondents within South Africa. The majority of respondents indicate that SBE is a valuable education tool. A number of barriers have been identified that limit the growth of SBE within South Africa. It is hoped that with a commitment to ongoing SBE research and evaluation, SBE can be grown in South Africa.

Keywords: simulation, South Africa, simulation-based education, anaesthesia, simulation training

\section{Introduction}

Simulation is defined by the Society for Simulation in Healthcare as: "A technique that creates a situation or environment to allow persons to experience a representation of a real event for the purpose of practice, learning, evaluation, testing, or to gain understanding of systems or human actions."1 By immersing the participant in this simulated reality, learning in relation to the created environment or situation can occur.

Medicine has traditionally adopted a 'see one, do one, teach one' approach to learning. ${ }^{2}$ Due to the nature of medicine and the steep learning curve, the costs of failure are high. Aggarwal et al propose: "Climbing the steep learning curve can no longer be done by trial and error, so it is necessary to explore, define and implement models of health professional training that do not expose the patient to preventable errors. One such model is simulation-based training." ${ }^{3}$ Simulation however does not only apply to individual training; it is also an excellent tool for team training and systems testing. ${ }^{4}$

Simulation is a tool that can be used as one part of an educational programme. A significant amount of research has shown evidence of the benefit associated with simulation-based education
(SBE). ${ }^{5-7}$ SBE can be defined as an educational or training method that is used to "replace or amplify real experience with guided experiences". 8 It is not defined by technology but rather by an educational approach. ${ }^{9}$

A systematic review of 34 years of healthcare simulation literature found that the use of high-fidelity simulations facilitates learning among trainees, when used under the right conditions. ${ }^{5} \mathrm{~A}$ second critical review of simulation-based medical education research provides further examples of the benefits of simulation education for clinical skill acquisition. ${ }^{6}$ Little is known about the current practices of SBE within South Africa, with limited published research relating to SBE in anaesthesia. ${ }^{10}$

The objectives of this study were to describe: i) the state of SBE in anaesthesia within South Africa and a selection of other settings; ii) the learner groups targeted with $\mathrm{SBE}$; iii) the tools used to assess performance during SBE events; iv) the learning objectives targeted; $v$ ) the evaluation of the quality and impact of SBE programmes; vi) the resources available within South Africa for SBE; vii) the perceived barriers to the implementation of SBE in South Africa; viii) the attitudes towards SBE; and ix) research and collaboration. 
Table I. Description of respondents' host institution and discipline

\begin{tabular}{lccccc}
\hline Institution & Medical school & $\begin{array}{c}\text { Teaching hospital } \\
\text { tertiary }\end{array}$ & $\begin{array}{c}\text { Teaching hospital } \\
\text { secondary }\end{array}$ & Private hospital & $\begin{array}{c}\text { Emergency } \\
\text { medical services }\end{array}$ \\
\hline No of respondents & 12 & 30 & 3 & 6 & 1 \\
\hline Discipline & $\begin{array}{c}\text { Education } \\
\text { department }\end{array}$ & Anaesthesia & Paediatrics & $\begin{array}{c}\text { Emergency } \\
\text { medicine }\end{array}$ & $\begin{array}{c}\text { Emergency } \\
\text { medical services }\end{array}$ \\
\hline No of respondents & 6 & 36 & 6 & 3 & 1 \\
\hline
\end{tabular}

This survey aims to provide a greater understanding of the current state of SBE in South Africa, facilitating further collaboration, research and growth.

\section{Methods}

Institutional ethics approval was obtained (HREC REF 157/2017). An online survey was created by the authors. REDCap ${ }^{\circledR}$ was used as the data capture system. The survey link was sent via the South African Society of Anaesthesiologists (SASA) mailing list. It was also sent via email to all SBE educators the authors could identify within South Africa via internet searches, telephonic contact and participation lists in local SBE courses. A repeat email was sent on two further occasions in an attempt to get a response from non-responders.

Respondents were divided into those answering on behalf of an SBE programme within an anaesthesia service, and those from a non-anaesthesia programme e.g. a multi-disciplinary educational unit within a university framework, in order to differentiate the two groups for analysis.

The survey was compiled using guidance from the Society of Simulation in Healthcare Accreditation Council document ${ }^{11}$ on accreditation standards, and Association of American Medical Colleges Medical Simulation in Medical Education survey. ${ }^{12}$

Likert-type questions were used to elicit attitudes towards SBE, baseline SBE use and perceived barriers to SBE use. Multiple tick-box closed questions were used for other topic areas with free-text response opportunities for more detail. The survey was piloted with a small group of simulation educators to test and refine the design. A copy of the survey is included in the supplementary material (on-line).

We report median results for each Likert-type question to describe central tendency. Prominent themes evident in the survey responses are highlighted and discussed. Comparative analysis was not performed because our sample-size was too small. Further results are available in the attached Appendix.

\section{Results}

\section{Demographics of responders}

A total of 1859 emails were sent, 60 responses were captured, of which six were incomplete. Respondents were based across 25 hospitals and/or institutions. There were 36 responses for the anaesthesia group and 18 for the non-anaesthesia group. The respondent demographics are shown in Table I.

Forty percent of anaesthesia respondents and 38\% of nonanaesthesia respondents reported having formal SBE accreditation (Supplementary Table I), but only $11 \%$ of all respondents reported attending a formal simulation instructor course (Supplementary Table II).

\section{The state of SBE in anaesthesia within South Africa and a selection of other settings}

The majority of respondents agree or strongly agree with the following statements: their department provides SBE; SBE is

Table II. The state of departmental SBE

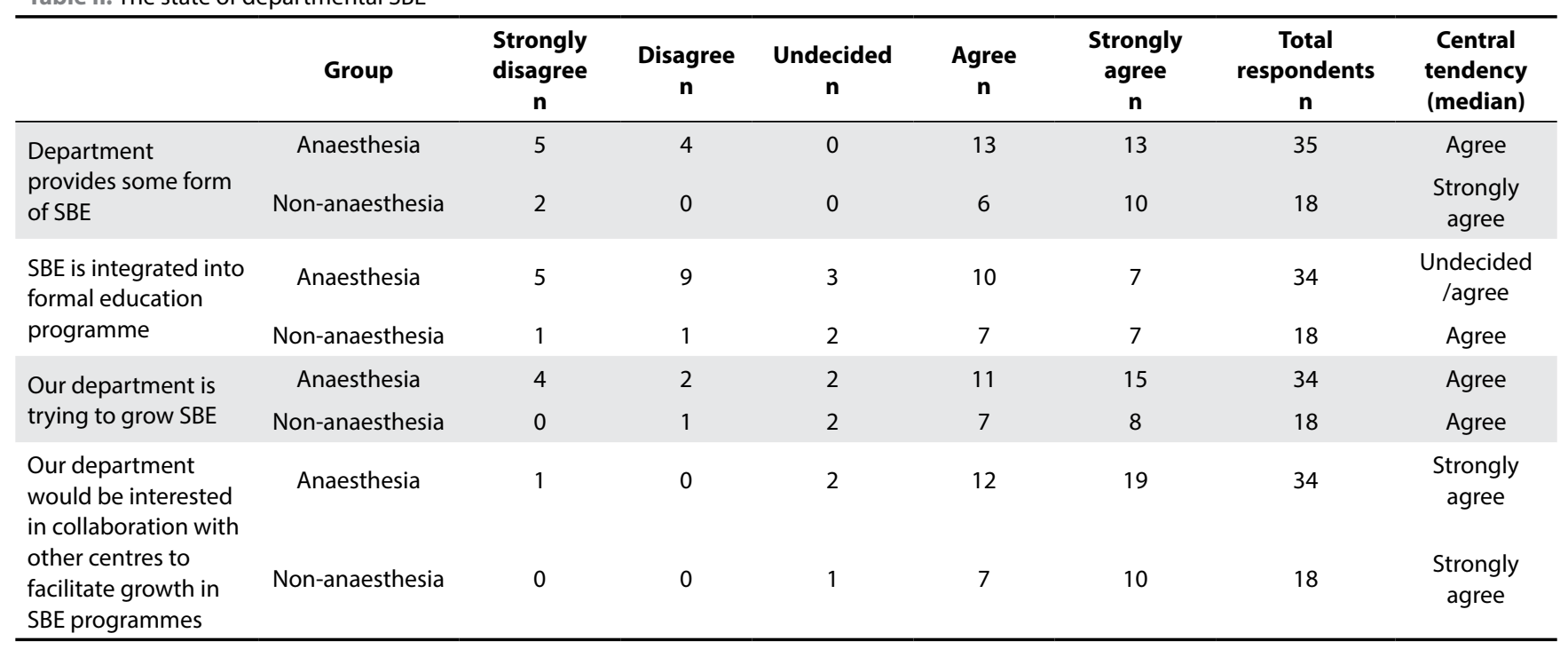


integrated into formal education programmes; departments are trying to grow SBE and are interested in collaboration. The state of departmental SBE is shown in Table II.

\section{The learner groups targeted with SBE in South Africa}

Anaesthesia respondents target registrars (69\%), medical interns (67\%) and undergraduates (53\%). Non-anaesthesia respondents target undergraduates (77\%), nurses (61\%) and registrars (61\%).

The user groups are shown in Table III.

Table III. The learner groups or staff targeted with SBE (\%)

\begin{tabular}{lcc}
\hline & Anaesthesia (\%) & Non-anaesthesia (\%) \\
\hline Nurses & 50 & 61 \\
\hline Paramedics & 6 & 27 \\
Undergraduates & 52 & 77 \\
\hline Medical interns & 67 & 44 \\
Medical officers & 47 & 33 \\
Registrars & 69 & 61 \\
Specialists & 31 & 33 \\
Teams within & 11 & 50 \\
department & & 55
\end{tabular}

\section{Assessing learner performance during SBE and learning objectives}

Anaesthesia respondents reported using SBE for summative assessment of nurses (9\%), interns (19\%), medical officers (3\%), registrars (11\%) and specialists (3\%). Non-anaesthesia respondents reported using SBE for summative assessment of nurses $(11 \%)$, interns $(11 \%)$, medical officers $(0 \%)$, registrars (44\%) and specialists (6\%). The most common technique for assessing the quality of learner performance during SBE was 'expert opinion' (33\%) for the anaesthesia group and validated checklists (56\%) for the non-anaesthesia group (Supplementary Figure 1).

The learning objectives targeted with SBE are shown in Figure 1.

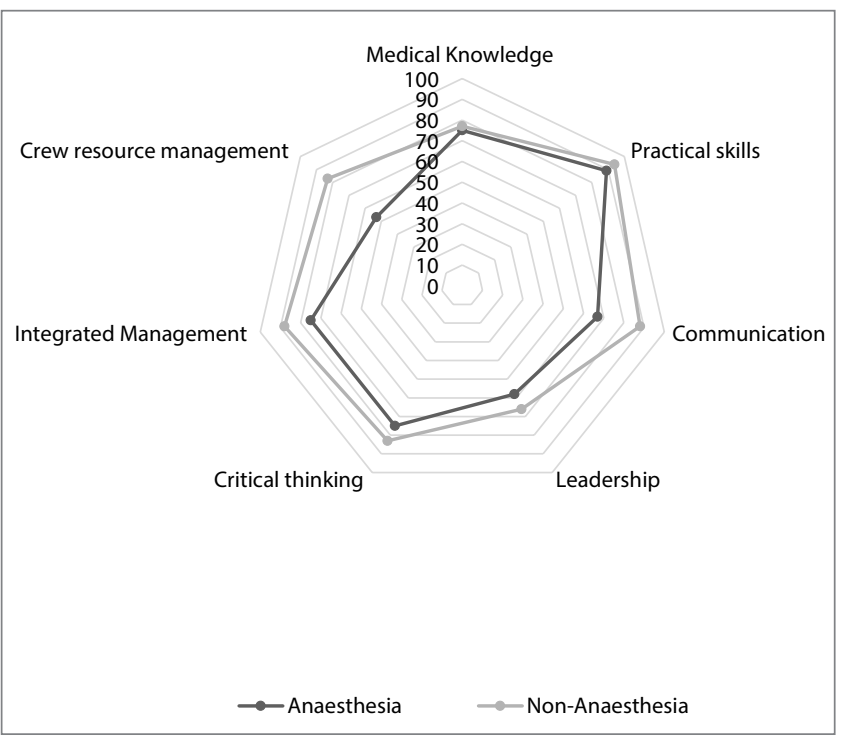

Figure 1. Learning objectives targeted with SBE (\% with positive responses)

\section{Quality and impact of SBE programmes}

The quality of the SBE programmes was predominantly evaluated using participant feedback (42\%). The evaluation methods are shown in Table IV.

The impact of SBE was evaluated by informal discussions and learner feedback. The methods used for evaluating the impact of SBE are shown in Table V.

\section{The resources available within South Africa for SBE}

In the anaesthesia group, SBE takes place more commonly within a dedicated on-site SBE facility (47\%) with $28 \%$ delivering 'in-situ' simulation. Non-anaesthesia SBE was more frequently performed in a dedicated on-site simulation facility (55\%). The location of SBE events is shown in Table VI.

Most respondents report access to a range of SBE equipment. Very few report access to virtual reality or haptic equipment. A

Table IV. Methods used for evaluation of SBE quality (\% with positive responses)

\begin{tabular}{|c|c|c|c|c|c|}
\hline & None & Peer-evaluation & Independent evaluation & Participant feedback & Other \\
\hline Anaesthesia & $22 \%$ & $22 \%$ & $8 \%$ & $42 \%$ & $8 \%$ \\
\hline Non-anaesthesia & $22 \%$ & $28 \%$ & $5 \%$ & $39 \%$ & $5 \%$ \\
\hline
\end{tabular}

Table V. Methods used for evaluation of impact of SBE (\% with positive responses)

\begin{tabular}{lcccc}
\hline & $\begin{array}{c}\text { Informal } \\
\text { discussion* }\end{array}$ & $\begin{array}{c}\text { Learner } \\
\text { feedback* }\end{array}$ & $\begin{array}{c}\text { Assessment of learner in } \\
\text { simulation* }\end{array}$ & $\begin{array}{c}\text { Assessment of learner in real } \\
\text { situation* }\end{array}$ \\
\hline Anaesthesia & $42 \%$ & $39 \%$ & $25 \%$ & $14 \%$ \\
Non-anaesthesia & $22 \%$ & $50 \%$ & $22 \%$ & $5 \%$ \\
\hline
\end{tabular}

*further explanation of the terms used is provided in the glossary section of the appendix

Table VI. Location of SBE events (\% with positive responses)

\begin{tabular}{lccc}
\hline & $\begin{array}{c}\text { Dedicated simulation facility } \\
\text { off-site }\end{array}$ & $\begin{array}{c}\text { Dedicated simulation facility } \\
\text { within facility }\end{array}$ & $\begin{array}{c}\text { Dedicated simulation facility } \\
\text { within department }\end{array}$ \\
\hline Anaesthesia & $6 \%$ & $47 \%$ & $22 \%$ \\
Non-anaesthesia & $5 \%$ & $55 \%$ & $5 \%$ \\
\hline
\end{tabular}


Table VII. Ownership of simulation space and equipment

\begin{tabular}{lcccccc}
\hline & \multicolumn{3}{c}{ Anaesthesia } & & \multicolumn{2}{c}{ Non-anaesthesia } \\
\cline { 2 - 6 } & Yes (\%) & No (\%) & Partial (\%) & Yes (\%) & No (\%) & Partial (\%) \\
\hline Sim space & 10 & 72 & 17 & 83 & 88 & 11 \\
Sim equipment & 38 & 41 & 20 & 0 & 11 \\
\hline
\end{tabular}

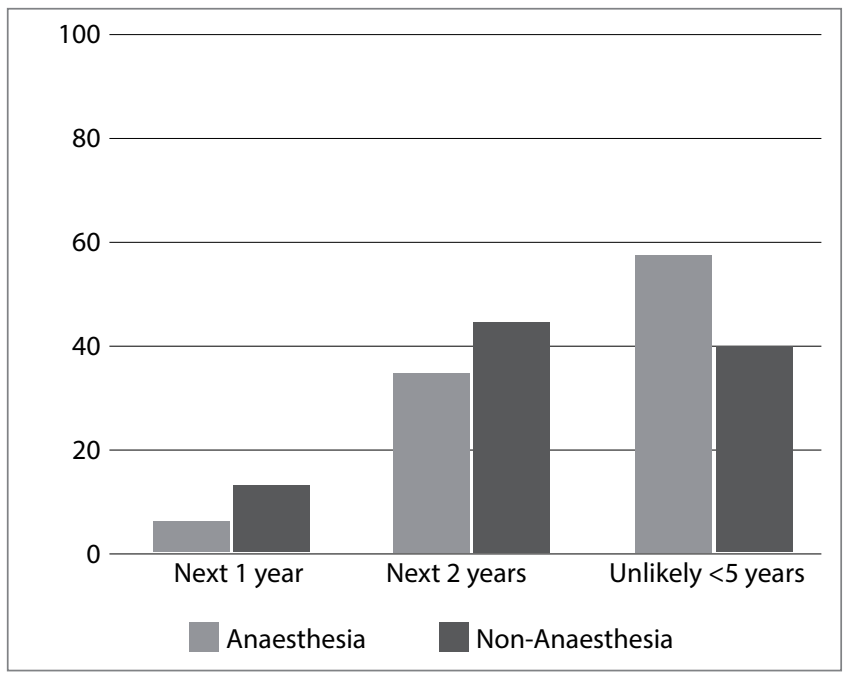

Graph 1. Likelihood to fulfil equipment needs (\% with positive response) response to questions about access to equipment is available in Supplementary Figures 2 and 3.

\section{Ownership of SBE resources}

Ten percent of anaesthesia respondents report total ownership of their simulation space and $38 \%$ report ownership of the equipment. Eighty-three percent of non-anaesthesia respondents own their simulation space and $88 \%$ report owning the equipment. Ownership of SBE space and equipment is shown in Table VII.

\section{Likelihood to fulfil equipment needs}

Close to $60 \%$ of the anaesthesia group and $40 \%$ of the nonanaesthesia group do not think they would fulfil their equipment needs in the next five years. The likelihood to fulfil equipment needs is shown in Graph 1.

Table VIII. Perceived barriers to and attitudes towards SBE

\begin{tabular}{|c|c|c|c|c|c|c|c|c|}
\hline & Group & $\begin{array}{c}\text { Strongly } \\
\text { disagree } \\
\mathbf{n} \\
\end{array}$ & $\begin{array}{l}\text { Disagree } \\
\mathbf{n}\end{array}$ & $\begin{array}{c}\text { Undecided } \\
\mathbf{n}\end{array}$ & $\begin{array}{l}\text { Agree } \\
\mathbf{n}\end{array}$ & $\begin{array}{c}\text { Strongly } \\
\text { agree } \\
\mathbf{n}\end{array}$ & $\begin{array}{c}\text { Total } \\
\text { respondents } \\
\mathbf{n}\end{array}$ & $\begin{array}{c}\text { Central } \\
\text { tendency } \\
\text { (median) }\end{array}$ \\
\hline \multirow{2}{*}{$\begin{array}{l}\text { Lack of finances for } \\
\text { simulation programme }\end{array}$} & Anaesthesia & 1 & 5 & 5 & 12 & 11 & 34 & Agree \\
\hline & Non-anaesthesia & 1 & 2 & 2 & 8 & 5 & 18 & Agree \\
\hline \multirow{2}{*}{ Lack of trained educators } & Anaesthesia & 0 & 7 & 3 & 14 & 9 & 33 & Agree \\
\hline & Non-anaesthesia & 0 & 2 & 1 & 11 & 4 & 18 & Agree \\
\hline \multirow{2}{*}{$\begin{array}{l}\text { Lack of space/facilities } \\
\text { dedicated to simulation }\end{array}$} & Anaesthesia & 3 & 13 & 2 & 10 & 6 & 34 & Undecided \\
\hline & Non-anaesthesia & 2 & 8 & 2 & 3 & 3 & 18 & Disagree \\
\hline \multirow{2}{*}{$\begin{array}{l}\text { Lack of simulation } \\
\text { equipment }\end{array}$} & Anaesthesia & 3 & 11 & 0 & 12 & 7 & 33 & Agree \\
\hline & Non-anaesthesia & 3 & 6 & 2 & 5 & 2 & 18 & $\begin{array}{l}\text { Disagree/ } \\
\text { undecided }\end{array}$ \\
\hline \multirow{2}{*}{$\begin{array}{l}\text { Lack of protected time for } \\
\text { educators }\end{array}$} & Anaesthesia & 2 & 1 & 2 & 11 & 18 & 34 & $\begin{array}{l}\text { Strongly } \\
\text { agree }\end{array}$ \\
\hline & Non-anaesthesia & 1 & 1 & 1 & 8 & 7 & 18 & Agree \\
\hline \multirow{2}{*}{$\begin{array}{l}\text { Lack of protected time for } \\
\text { learners }\end{array}$} & Anaesthesia & 1 & 3 & 0 & 11 & 19 & 34 & $\begin{array}{l}\text { Strongly } \\
\text { agree }\end{array}$ \\
\hline & Non-anaesthesia & 1 & 3 & 1 & 7 & 6 & 18 & Agree \\
\hline \multirow{2}{*}{$\begin{array}{l}\text { Lack of institutional } \\
\text { support for SBE }\end{array}$} & Anaesthesia & 1 & 10 & 6 & 9 & 8 & 34 & $\begin{array}{l}\text { Undecided/ } \\
\text { agree }\end{array}$ \\
\hline & Non-anaesthesia & 4 & 4 & 1 & 6 & 3 & 18 & $\begin{array}{l}\text { Undecided/ } \\
\text { agree }\end{array}$ \\
\hline \multirow{2}{*}{$\begin{array}{l}\text { Simulation is not } \\
\text { yet validated as an } \\
\text { educational model }\end{array}$} & Anaesthesia & 10 & 17 & 5 & 1 & 1 & 34 & Disagree \\
\hline & Non-anaesthesia & 9 & 6 & 2 & 1 & 0 & 18 & $\begin{array}{l}\text { Strongly } \\
\text { disagree/ } \\
\text { disagree }\end{array}$ \\
\hline \multirow{2}{*}{$\begin{array}{l}\text { Simulation is perceived as } \\
\text { stressful and intimidating }\end{array}$} & Anaesthesia & 11 & 12 & 6 & 4 & 0 & 33 & Disagree \\
\hline & Non-anaesthesia & 5 & 5 & 4 & 3 & 1 & 18 & Disagree \\
\hline
\end{tabular}


Table IX. Respondents conducting research

\begin{tabular}{lccc}
\hline & $\begin{array}{c}\text { Quantitative into sim efficiency } \\
\mathrm{n}(\%)\end{array}$ & $\begin{array}{c}\text { Quantitative with sim as } \\
\text { vehicle }\end{array}$ & $\begin{array}{c}\text { Qualitative into how and } \\
\text { why sim works }\end{array}$ \\
\hline Anaesthesia & $8(22 \%)$ & $4(11 \%)$ & $5(14 \%)$ \\
Non-anaesthesia & $3(16 \%)$ & $1(5 \%)$ & $4(11 \%)$ \\
\hline
\end{tabular}

\section{The perceived barriers to the implementation of SBE in South Africa and attitudes towards SBE}

The main barriers to SBE were the following: available finances for SBE, lack of trained educators, lack of equipment and lack of protected time for educators and learners. Respondents did not see the validation of SBE as a barrier to implementation. Furthermore, SBE being perceived as stressful or intimidating was not seen as a barrier. A lack of space or facilities were not reported as barriers to SBE implementation. The perceived barriers and attitudes to SBE are shown in Table VIII.

\section{Research and collaboration}

Only a limited number of respondents report engaging in SBE research. A desire to collaborate with other centres is reported by $96 \%$ of the anaesthesia respondents and $89 \%$ of non-anaesthesia respondents. SBE research is shown in Table IX.

\section{Discussion}

Simulation-based education as a model for training is well established in international literature. ${ }^{12}$ South Africa is experiencing growth in SBE in anaesthetic postgraduate training programmes and continuous professional development (CPD) programmes. ${ }^{10,13}$ To the best of our knowledge this is the first cross-sectional study of the perceptions and attitudes towards SBE in South Africa. Understanding SBE within the context of anaesthesia will allow for its further development and growth.

\section{Demographics of responders}

The majority of respondents were from tertiary institutions. In South Africa all tertiary institutions exist within the public health system. The bias seen in this response is likely due to a combination of the method of data collection and the more frequent utilisation of SBE in training programmes. Despite respondents' perceptions of formal simulation faculty accreditation, closer inspection of the survey responses indicate that only $11 \%$ of simulation instructors have formal simulation accreditation. This is an area of SBE in South Africa that should be targeted to expand the delivery of high quality simulation.

\section{The state of SBE in anaesthesia within South Africa and a selection of other settings}

The integration of SBE into formal teaching programmes, in the South African context, mirrors the growing international trend of this form of education. ${ }^{14}$ It is encouraging to note the will to further develop SBE within the individual centres. The willingness of respondents to collaborate across institutions must be supported and encouraged in order to grow SBE in both anaesthesia and other settings.

\section{The learner groups targeted with SBE}

Undergraduates, medical interns, registrars and nurses are the primary learners targeted. This is similar to the groups targeted internationally. ${ }^{14}$ The profile of learner groups may explain the learning objectives reported in the survey. Practical skills, medical knowledge, critical thinking and integrated management were the predominant targets of the anaesthesia respondents. This is contrasted by the non-anaesthesia respondents that target crew resource management and communication to a greater degree. Anaesthesia learner groups may benefit from expansion of the skills targeted in their SBE programmes. In one international survey, skill acquisition, patient safety, communication, and collaboration are reported as the most frequently targeted learning outcomes. ${ }^{14}$ However, the fact that crew resource management is not a primary target in our anaesthesia respondents poses questions about training priorities in South Africa compared to a decades-old tradition of targeting crew resource management as seen in international literature. ${ }^{8,15,16}$

\section{The SBE tools of assessment and learning objectives}

The most common tool for assessing the quality of learner performance during SBE for summative assessment was 'expert opinion' (33\%) for the anaesthesia group and validated checklists (56\%) for the non-anaesthesia group. Expert opinion is potentially subjective and influenced by local practice. A more objective method of assessment should be implemented to ensure high quality outcomes. It is also important that evaluation tools or checklists undergo both frequency of endorsement and a test of homogeneity using analysis of internal consistency. ${ }^{17}$

\section{Quality and impact of SBE programmes}

Very few of the respondents evaluated the quality or the impact of SBE. This may be due to the relatively new adoption of SBE as a learning tool within South Africa. Participant feedback was mainly used to evaluate SBE quality. This method is potentially subjective and unreliable. Educational impact on more objective indicators such as improved clinical outcomes is difficult to measure or achieve. Currently, informal discussions and learner feedback are most frequently used to evaluate the impact of SBE. SBE literature has examples of measurable educational interventions resulting in improved clinical outcomes.,18 An example of this is the use of SBE to improve central venous catheterisation outcomes. ${ }^{19}$ 


\section{The resources available within South Africa for SBE}

The majority of SBE appears to be taking place within dedicated simulation facilities. In-situ SBE appears to be underutilised. Expensive high-tech equipment is not necessary for effective SBE provision. ${ }^{20}$ It is possible to provide high quality SBE with a limited financial budget. This is important within the South African context as most institutions have limited budgets. The authors' SBE programme is able to provide in-situ simulation events in unused clinical areas such as vacant operating theatres at very little cost. Utilising existing clinical areas provides the added benefit of testing the systems in place to care for patients in these areas. ${ }^{21}$

The only categories of equipment that most respondents had no access to were virtual reality and haptic systems. Most respondents had some access to the majority of SBE equipment. Haptic equipment is described as, "replicating the kinaesthetic and tactile perception"4; these include intubation models and regional phantoms in anaesthesia. Online simulation modules, task trainers, low fidelity human patient simulation, and high fidelity human patient simulation were the most frequently used equipment internationally. ${ }^{14}$

Only $10 \%$ of anaesthesia respondents report total ownership of simulation space, while 38\% report total ownership of simulation equipment. This is in contrast to non-anaesthesia respondents where $83 \%$ report owning their simulation space and $88 \%$ their equipment. This suggests that anaesthetic programmes have been able to launch their simulation programmes without the capital outlay inherent in establishing a dedicated simulation space and acquiring equipment. It is unclear what the implications of low-levels of ownership of simulation space or equipment are for the anaesthesia respondents.

Non-anaesthesia respondents believe they are more likely to fulfil their equipment needs within the next five years, as opposed to almost $60 \%$ of anaesthesia respondents who report they will not be able to do so. We can only speculate about the barriers to acquisition of SBE equipment, but the increasing financial strain on the South African healthcare sector must be contributory. The volatility of the rand may impact on budget planning which may limit the ability to purchase the desired equipment. For SBE to grow as a modality, it needs to be integrated into curricula at University, College of Medicine, and HPCSA levels. It could also be integrated into the service delivery models of hospitals and hospital groups for the value it provides in teamwork training and systems testing. ${ }^{21}$

\section{The perceived barriers to the implementation of SBE in South Africa and attitudes towards SBE}

The lack of protected time for SBE was a prominent theme throughout free text survey responses. The lack of protected time may reflect the challenges faced by health professionals within the South African healthcare context. Limited financial resources made available for SBE is likely to result in the slower than desired growth of SBE. Anaesthesia respondents, in particular, felt that an inability to obtain simulation equipment would be a barrier to SBE implementation in their programmes. Developing SBE programmes acknowledge the lack of trained educators as a barrier to their growth. When compared to international literature the top two barriers listed in this survey were the need for more financial support and the need for a dedicated simulation technician. ${ }^{14}$

The issue of psychological safety in SBE has been reported in the literature. ${ }^{22}$ Despite the fact that SBE may be perceived as stressful and intimidating, respondents did not perceive this as a barrier to its use. This may also be due to the fact that the survey reflects the views of enthusiasts already providing SBE and this interesting point should be investigated further.

\section{Research and collaboration}

Although there appears to be a wide range of research currently being conducted by respondents, this is not currently being translated into publications on SBE in South Africa. It is promising that $96 \%$ and $89 \%$ of the anaesthesia and non-anaesthesia groups respectively are interested in collaborations. It is hoped that future collaborations will result in a greater output of publications and hence awareness of SBE in the South African healthcare environment. A Simulation Special Interest Group has been formed under the banner of the South African Association of Health Educationalists, but a national coordinating simulation body does not yet exist.

\section{Strengths and weaknesses of the study}

This is the first study that attempts to describe SBE in anaesthesia and other settings within South Africa. A broad range of SBErelated topics have been covered. Allowing for anonymous responses to be recorded promoted frank reporting of the situation at respondents' hospitals and programmes. It is hoped that the publication of the survey results will increase SBE visibility and may improve response rates to future surveys.

The low number of respondents limits the rigour with which the data can be interrogated, but may reflect that only a small proportion of South African anaesthetists and other clinicians are actually involved in SBE. Individuals with an interest in SBE are more likely to respond thus creating a selection bias. While a spread of responses from several different institutions was received, some centres had more respondents than others. Due to the varying roles within an institution's SBE programme we believe responses have not been duplicated and thereby limit the impact this may have on the results. Furthermore, the individual views of respondents were targeted and individuals within a department or faculty may been involved in different SBE activities. There may be established units that have SBE providers who are not part of SASA and who remain unknown to the authors. 


\section{Strengths and weaknesses in relation to other studies}

There are no other studies of this nature regarding SBE in South Africa with which to compare the data. An international survey was found in which similar themes have been reported. ${ }^{14}$

\section{Implications for clinicians or policymakers}

SBE is an effective teaching tool. ${ }^{5,6}$ It is relatively new within South Africa although it is increasingly being incorporated into formal teaching programmes. Currently the main barriers appear to be a combination of financial and human resources. SBE needs to be assessed in a more objective manner in order to ensure high quality education is being provided.

\section{Unanswered questions and future research}

Very little assessment of the quality and impact of SBE has been conducted in South Africa. SBE proponents, in anaesthesia and non-anaesthesia groups, would do well to formalise their impact assessment strategies with a view to approaching hospital and university leadership as motivation for increased funding. Impact assessment of SBE may provide an opportunity to change the way regulators and funders view this educational modality in South Africa.

The authors suggest the formation of a national SBE collaborative group. This will allow the pooling of skills, knowledge and experience in order to improve SBE assessment and growth capacity.

\section{Conclusion}

This survey highlights several important points. SBE is increasingly being incorporated in to training programmes at a variety of levels in South Africa. In order to realise the maximal benefit of SBE there is a need to: increase the protected time available for $\mathrm{SBE}$; develop courses within South Africa to accredit trainers; and encourage the engagement and publication of SBE research and collaboration. Finally the authors suggest the establishment and creation of a national co-ordinating simulation body in South Africa.

\section{Acknowledgments}

Many thanks to Prof Bruce Biccard for his assistance with the editing of this paper.

\section{Declaration of interest}

Dr Robert Swart has no financial or academic conflicts of interest. Dr Rowan Duys is currently a Fellow in Simulation and Education sponsored by Dräger.

Dr Neil Hauser has no conflicts of interest to declare.

\section{Authors' contributions}

The research paper and all related materials were created by $\mathrm{Dr}$ Robert Swart and Dr Rowan Duys. Dr Neil Hauser contributed to the writing of this paper.

\section{References}

1. Lopreiato JO. Healthcare Simulation Dictionary. Rockville MAfHRaQOAPN-. 2016.

2. Rodriguez-Paz JM, Kennedy M, Salas E, et al. Beyond "see one, do one, teach one": toward a different training paradigm. Postgrad Med J 2009;85:244-9. 10.1136/qshc.2007.023903: 10.1136/qshc.2007.023903.

3. Aggarwal $R$, Mytton OT, Derbrew $M$, et al. Training and simulation for patient safety. Qual Saf Health Care 2010;19 Suppl 2:i34-43. 10.1136/qshc.2009.038562: 10.1136/qshc.2009.038562.

4. Bradley P. The history of simulation in medical education and possible future directions. Med Educ 2006;40:254-62. 10.1111/j.1365-2929.2006.02394.x: 10.1111/j.1365-2929.2006.02394.x.

5. Issenberg SB, McGaghie WC, Petrusa ER, Lee Gordon D, Scalese RJ. Features and uses of high-fidelity medical simulations that lead to effective learning: a BEME systematic review. Med Teach 2005;27:10-28. 10.1080/01421590500046924: 10.1080/01421590500046924.

6. McGaghie WC, Issenberg SB, Petrusa ER, Scalese RJ. A critical review of simulation-based medical education research: 2003-2009. Med Educ 2010; 44:50-63. 10.1111/j.1365-2923.2009.03547.x: 10.1111/j.1365-2923.2009.03547.x.

7. Seaton $P$, Levett-Jones $T$, Cant $R$, Cooper $S$. Exploring the extent to which simulation-based education addresses contemporary patient safety priorities: A scoping review. Collegian 2019;26:194-203.

8. Gaba DM. The future vision of simulation in health care. Qual Saf Health Care 2004; 13 Suppl 1: i2-10.10.1136/qhc.13.suppl_1.i2: 10.1136/qhc.13.suppl_1.i2.

9. Aebersold M. Simulation-based learning: No longer a novelty in undergraduate education. OJIN: The Online Journal of Issues in Nursing 2018;23.

10. Horsten $G$, Wise R, Ramroop S, Rodseth R. The development of a scoring tool for the measurement of performance in managing hypotension and intra-operative cardiac arrest during spinal anaesthesia for caesarean section. Southern African Journal of Anaesthesia and Analgesia 2015;21:17-23. 10.1080/22201181.2015.1054617: 10.1080/22201181.2015.1054617.

11. Society for Simulation in Healthcare. Council for Accreditation of Healthcare Simulation Programs Accreditation Standards Self-Study Review. 2014; (January):1-25.

12. Passiment MSH, Huang G. Medical simulation in medical education: Results of an AAMC survey. 2011. Available from https://www.aamc.org/download/259760/ data.

13. Hillerman C. Anaesthetic simulation, and education and training in South Africa. South African Journal of Anaesthesia and Analgesia 2015;21

14. Qayumi $K$, Pachev $G$, Zheng $B$, et al. Status of simulation in health care education: an international survey. Adv Med Educ Pract 2014;5:457-67. 10.2147/AMEP. S65451: 10.2147/AMEP.S65451.

15. Fletcher G, Flin R, McGeorge P, Glavin R, Maran N, Patey R. Anaesthetists' Non-Technical Skills (ANTS): evaluation of a behavioural marker system. Br J Anaesth 2003;90:580-8. 10.1093/bja/aeg112: 10.1093/bja/aeg112.

16. Krage R, Erwteman M. State-of-the-art usage of simulation in anesthesia: skills and teamwork. Curr Opin Anaesthesiol 2015;28:727-34. 10.1097/ ACO.0000000000000257: 10.1097/AC0.0000000000000257.

17. Morgan PJ, Cleave-Hogg D, DeSousa S, Tarshis J. High-fidelity patient simulation: validation of performance checklists. Br J Anaesth 2004;92:388-92. 10.1093/bja/ aeh081: 10.1093/bja/aeh081.

18. Murray AW, Beaman ST, Kampik CW, Quinlan JJ. Simulation in the operating room. Best Pract Res Clin Anaesthesiol 2015;29:41-50. 10.1016/j.bpa.2015.02.005: 10.1016/j.bpa.2015.02.005.

19. Ma IWY, Brindle ME, Ronksley PE, Lorenzetti DL, Sauve RS, Ghali WA. Use of simulation-based education to improve outcomes of central venous catheterization: a systematic review and meta-analysis. Academic Medicine 2011;86:1137-47. 10.1097/ACM.0b013e318226a204: 10.1097/ ACM.0b013e318226a204.

20. Maran NJ, Glavin RJ. Low- to high-fidelity simulation - a continuum of medical education? Med Educ 2003;37 Suppl 1:22-8.

21. Rall M, Dieckmann P. Simulation and patient safety: The use of simulation to enhance patient safety on a systems level. Current Anaesthesia \& Critical Care 2005;16:273-81. 10.1016/j.cacc.2005.11.007: 10.1016/j.cacc.2005.11.007.

22. Rudolph JW, Raemer DB, Simon R. Establishing a safe container for learning in simulation: the role of the presimulation briefing. Simul Healthc 2014;9:339-49. 10.1097/SIH.0000000000000047: 10.1097/SIH.0000000000000047. 


\section{Appendix 1}

\section{The SBE tools of assessment and learning objectives}

Anaesthesia most common tool was expert opinion (33\%). Non-anaesthesia most common tool was validated checklists (56\%).

The tools used for assessment during SBE events are shown below in Supplementary Figure 1.

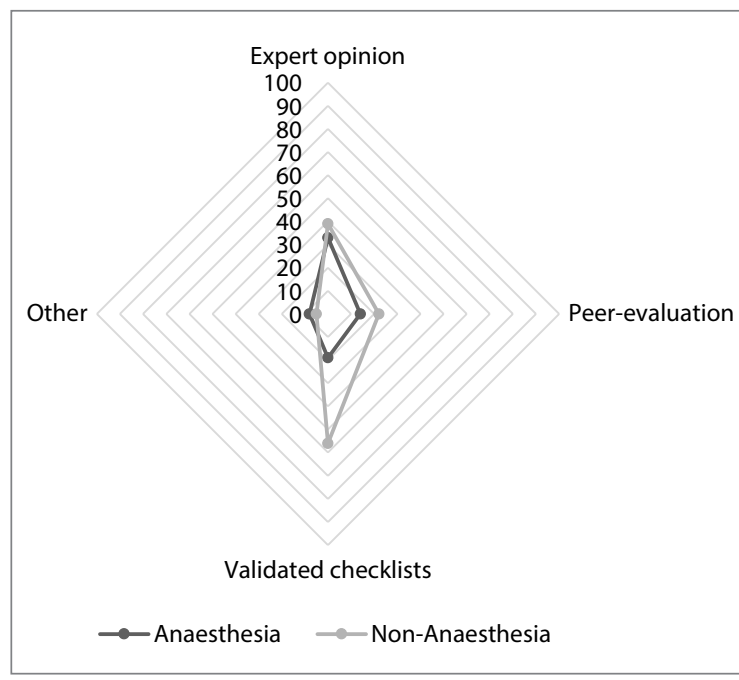

Supplementary Figure 1. Tools for assessment (\% positive response)

Supplementary Table I. Protected time and accreditation (\% positive response)

\begin{tabular}{lcccc}
\hline & \multicolumn{2}{c}{ Anaesthesia } & \multicolumn{2}{c}{ Non-anaesthesia } \\
\cline { 2 - 5 } & Yes (\%) & No (\%) & Yes (\%) & No (\%) \\
\hline $\begin{array}{l}\text { Protected time } \\
\text { present }\end{array}$ & 47 & 53 & 50 & 50 \\
Accreditation & 40 & 60 & 38 & 62 \\
\hline
\end{tabular}

Supplementary Table II. Formal simulation instructors course

\begin{tabular}{lc}
\hline Name of course & Number of respondents \\
\hline BASIM & 3 \\
Basic simulation instructor workshop & 1 \\
APLS & 1 \\
Local & 1 \\
MEPA & 1 \\
Bristol simulation centre & 1 \\
\hline Generic instructors course & 1 \\
\hline
\end{tabular}

\section{The resources available within South Africa for SBE}

The only category of equipment that most respondents had no access to was virtual reality and haptic. Most respondents had some access to the majority of SBE equipment. Access to equipment is shown in Supplementary Figures 2 and 3.

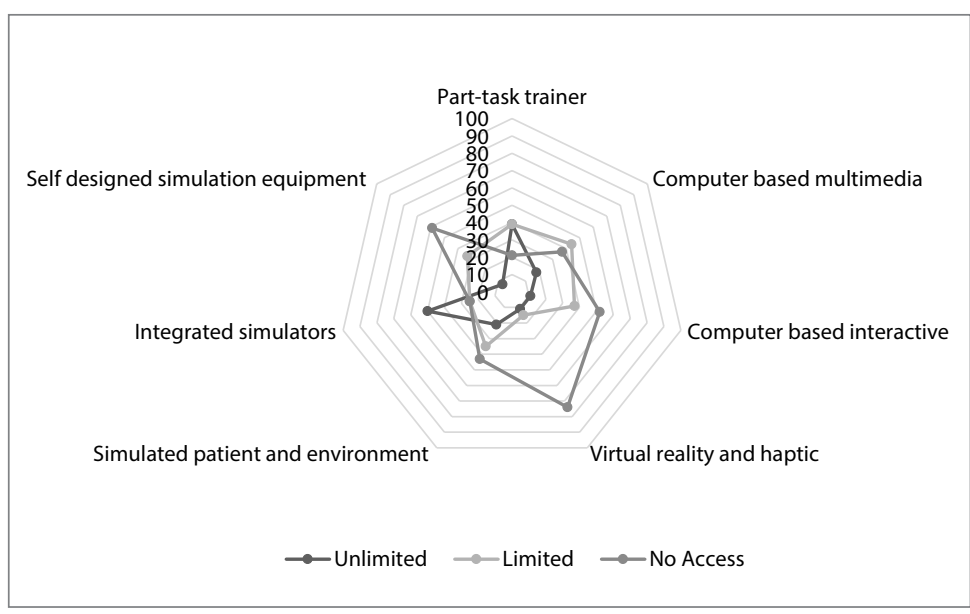

Supplementary Figure 2. Access to equipment: Anaesthesia (\% positive response)

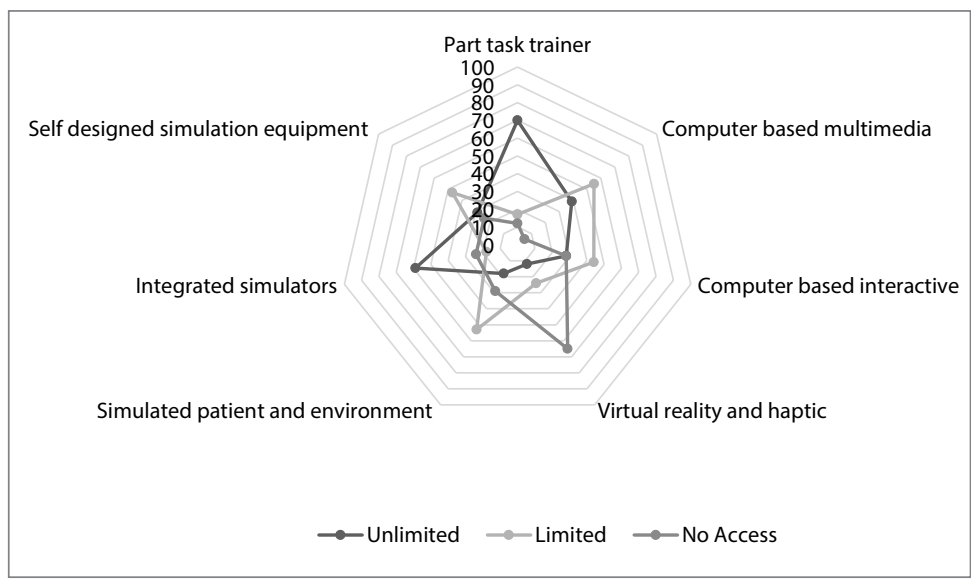

Supplementary Figure 3. Access to equipment: Non-anaesthesia (\% positive response)

\section{The perceived barriers to the implementation of SBE in South Africa and attitudes towards SBE}

When discussing the barriers to SBE anaesthesia and nonanaesthesia, groups were asked specifically about whether protected time for SBE was allocated or not, $47 \%$ and $50 \%$ answered Yes respectively. Forty percent of the anaesthesia group had SBE providers who were formally accredited, nonanaesthesia group had 38\%.

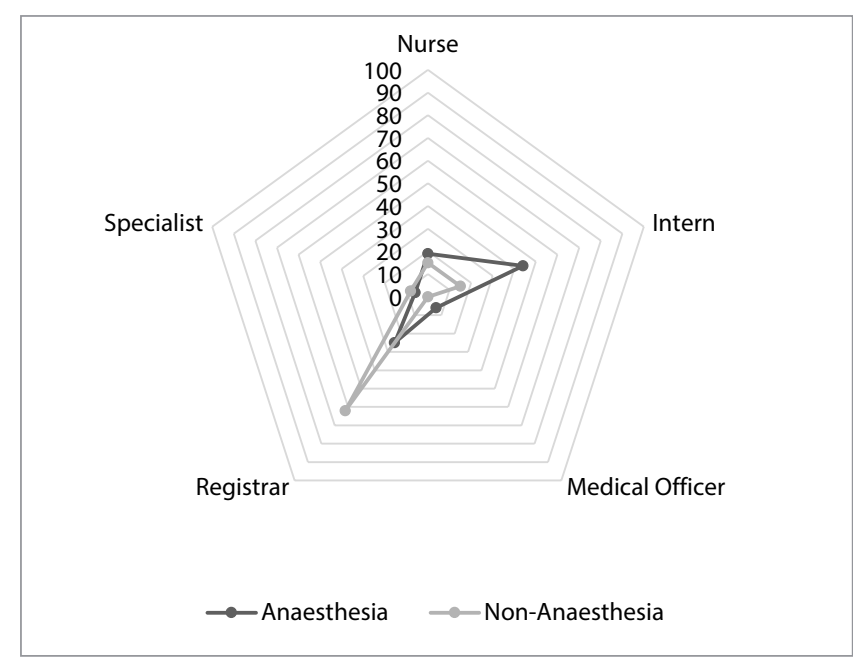

Supplementary Figure 4. Simulation for assessment (\% positive response) 


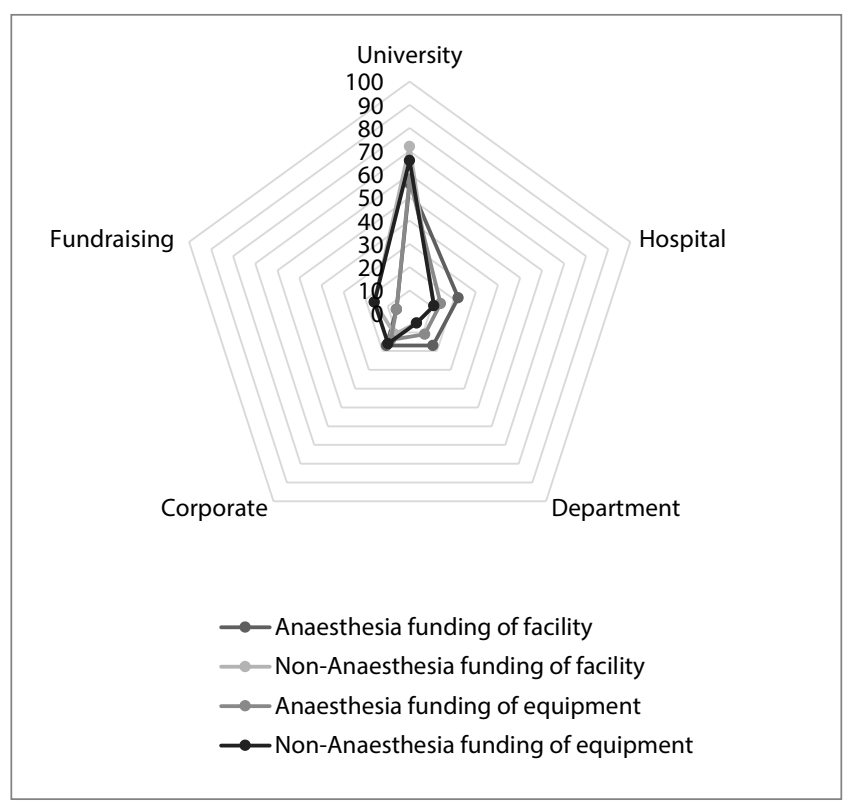

Supplementary Figure 5. Funding of facility and equipment (\% positive response)

\section{Glossary}

Methods used for evaluation of impact of SBE.

Informal discussions: These are discussions by the SBE faculty to determine the impact of the training provided. This is largely expert opinion based.

Leaner feedback: The impact of the SBE is determined by data collected from learners.

Assessment of learner in simulation: The improvement of the learner is assessed by a rating tool.

Assessment of the learner in real situation: Lessons learnt in simulation are subsequently assessed in the clinical environment using a rater scale assessment model.

Patient outcomes: Real life patient outcomes are determined to assess the impact of the SBE 